\title{
Affiliation and alignment in responding actions
}

\section{Introduction}

Recent years have seen a growing conversation-analytic interest in responding actions, as exemplified in several edited volumes and debates (Angouri and Locher, 2012; Stivers and Rossano, 2010, and replies to their article; Stivers et al., 2010; Thompson et al., 2015). Responding actions are specific to the type of initiating action they are constructed as responses to (Heritage, 1984; Schegloff, 2007; Thompson et al., 2015), and various aspects of responding actions can be shown to be closely fitted with, and mobilized somewhat distinctively depending on, the corresponding (type of) initiating action (Thompson et al., 2015; see also Pomerantz and Heritage, 2013). These include preference, lexico-grammatical features, prosody, timing, turn-design and visual conduct, among others. What is becoming increasingly evident from the aforementioned body of research is the need for further fine-grained examination of (a) the complex interplay of such aspects of responding actions, (b) how they are made relevant by various initiating or prior actions, and (c) the issue of universality versus cultural/linguistic specificity based on the investigation of a larger array of languages.

The present special issue aims to contribute new insights into our understanding of the linkages between different initiating actions and associated responding actions, particularly along the dimensions of (dis)affiliation and (dis)alignment - where affiliation pertains to the affective or action level of cooperation, and alignment to the structural level of cooperation (Stivers, 2008; Stivers et al., 2011). Steensig (2013) points out the need for future studies to shed further analytical light on the processes that they respectively involve. Each of the articles in this special issue explores an aspect of such processes in responding actions based on data from recordings of naturally occurring interactions in typologically different languages - Cantonese, English, Japanese, Korean, and Russian. Across these languages, the articles scrutinize processes in which either affiliation or alignment is made relevant, oriented to, or displayed, by the participants in responding actions. It is suggested that the distinctive relevancies of affiliation and/or alignment can be triggered and shaped within the given linguistic and interactional environments by particular types and formats of initiating actions or responding actions. Before providing an overview of the individual contributions, we start by briefly reviewing the concept of preference (which is often linked with affiliation and alignment), followed by short discussions of the notions of affiliation and alignment.

\section{Preference in responding actions}

Despite its connotations, the concept of preference does not pertain to psychological proclivities, but rather, describes "conversational events in which alternative, but non-equivalent, courses of action are available to the participants (Sacks, 1973)" (Atkinson and Heritage, 1984: 53). Preference operates on a wide range of interactional domains such as referring expressions, initiating actions, repair, turn-taking, and the progression of sequences or activities (Pomerantz and Heritage, 2013). With respect to responding actions in particular, preference addresses non-equivalent, asymmetrical, alternative types of response to specific initiating actions, as reviewed in Levinson (1983), Heritage (1984), and Pomerantz and Heritage (2013). For instance, with regard to preferred responses to first actions such as assessments, invitations, and requests, much attention has been paid to possible design features such as structural simplicity and contiguity - i.e. quick timing or close placement of the response relative to the initiating action, and vice versa for 
dispreferred responses (see contributions in this issue by Tanaka; Luke and Tanaka). ${ }^{1}$ In the case of responses to polar questions, a confirming, agreeing answer is preferred over a disconfirming, disagreeing answer (Sacks, 1987; Raymond, 2003). The preferred alternative, a confirming answer, occurs more frequently and is placed contiguously with the question, typically formatted as a straightforward answer; the dispreferred, disconfirming answer, by contrast, tends to be produced with more delay, and is normally formatted with accounts and mitigations (Sacks, 1987; Stivers et al., 2009; cf. contributions in this issue by Bolden and Lee).

Classic discussions of preference in responding actions have been closely tied to the notions of affiliation and alignment. Heritage (1984) describes preferred responses to a variety of initiating actions such as requests, offers, invitations, assessments, etc., as normally "affiliative actions which are supportive of social solidarity", and dispreferred responses as disaffiliative and "destructive of social solidarity" (Heritage, 1984: 268; see also Clayman, 2002). The specific features of preferred and dispreferred format responses are thus described as related to their affiliative and disaffiliative characters respectively (Heritage, 1984). Although not using the terms (dis)affiliation in the same way as used here, Pomerantz (1984) also suggests that in the case of responses to impersonal assessments, agreements are preferred, by noting that the participants orient to agreement as the invited (and hence affiliative) option by accomplishing sociability, support, and solidarity.

Schegloff (2007) subsequently turned attention to the structural relationship between sequence parts, describing responses embodying alignment with the project of the initiating action as preferred (though not necessarily affiliating with its speaker), and responses distancing from it as dispreferred. Preference in this sense is thus related to whether or not there is structural alignment with the activity or course of action the initiating action is designed to implement, which also relates to the progression of the sequence and its activity. Such discussions of preferred and dispreferred responses indicate that the organization of preference of responding actions is intimately interwoven with social affiliation and structural alignment.

\section{Affiliation in responding actions}

The concepts of affiliation and alignment have often been discussed in connection with one another, and it is fairly recently that these concepts have come to be treated as distinctive from one another. Stivers (2008) was the first to explicate and distinguish the two concepts explicitly, in particular, in mid-telling environments during storytelling. She conceptualizes affiliation in terms of the hearer's support and endorsement of the storyteller's affective stance toward, or treatment of, the events being described. This is understood as being separate from the concept of alignment, which is put forward as the hearer's support of the storytelling activity, i.e. of its structural asymmetry, in that the teller proposes to hold the floor until completion of the story (Stivers, 2008; see Section 4 below).

Developing and generalizing this conceptualization beyond storytelling contexts, Stivers et al. (2011) extend the term affiliation to refer to cooperation "at the level of action and affective stance" (p. 21). More specifically, affiliative responses are said to be "maximally pro-social when they match the prior speaker's evaluative stance, display empathy and/or cooperate with the preference of the prior action" (Stivers et al., 2011: 21). Thus, affiliative responses can involve two interrelated but slightly different facets, one of which concerns degrees of support for the prior speaker's affective stance, as in the context of storytelling (Stivers, 2008) or troubles-telling (e.g., Jefferson, 1988), and the other, whether the response accords with the action preference set in motion by the initiating action, as in preferred responses to initiating actions of requests, offers, invitations, etc. (see Heritage, 1984).

Conversation-analytic research on affiliative responses has explored a wide range of resources (e.g. verbal, prosodic, and visible) participants use in conveying (dis)affiliation, in connection with specific types of initiating actions and activities as well as sequential positions (Lindström and Sorjonen, 2013). For instance, Pomerantz (1984) focuses on verbal resources and formats for affiliation in responding to first assessments. She shows that respondents can provide strong agreement and affiliation by adding an intensifier to the same syntactic format and evaluative term used in the first, impersonal assessment. Heritage (2011) suggests gradations of affiliation in responding to the telling of personal experience. He shows that response cries - which do not discriminate between the teller's feelings associated with the event and the respondent's sentiments - are more affiliative than other types of verbal responses such as parallel assessments. Couper-Kuhlen (2012), in her study on the reception of complaint stories, explicates the role of verbal and prosodic resources for conveying (dis)affiliation, for instance, that verbal resources for affiliative reception, such as claims of understanding, congruent negative assessments, and by-proxy justification, may be accompanied by prosodic matching or upgrading. In addition, the same tokens of response cries and sound objects can convey affiliation when delivered with prosodic matching or upgrading, but disaffiliation when delivered with prosodic downgrading. In a recent

\footnotetext{
${ }^{1}$ But see Kendrick and Torreira (2015), suggesting that the timing of preferred and dispreferred responses is not as straightforward as previously thought.
}

Please cite this article in press as: Lee, S.-H., Tanaka, H., Affiliation and alignment in responding actions. Journal of Pragmatics (2016), http://dx.doi.org/10.1016/j.pragma.2016.05.008 
groundbreaking study, Thompson et al. (2015) systematically charts the relationship between syntactic formats and interactional functions (including affiliation and disaffiliation) in responding to a wide range of first actions and activities. Stivers, in the aforementioned study (2008), discusses the role of nodding as an example of a visible resource for claiming access to, and thereby affiliating with, the teller's stance in mid-telling positions during storytelling.

Importantly, resources used to convey (dis)affiliation can have varying implications depending on the sequential positions in which they occur. To cite Stivers (2008) again, she shows that the very resources for displaying affiliation in mid-telling positions - head nods - are treated as disaffiliative at story completion; instead, affiliative reception at story completion can be accomplished with verbal resources of providing assessments or second stories, thereby mirroring the teller's stance. The role of sequential position in displaying affiliation is also emphasized in Jefferson (2002) and Sorjonen (2001), respectively, demonstrating that response tokens such as no in American and British English (Jefferson, 2002) and $n i i(n)$ in Finnish (Sorjonen, 2001) can be used for displaying affiliation only in certain sequential positions. Jefferson (2002) also suggests the role of culture and institutional setting in coloring the particular character of no as affiliative (or not).

Prior studies thus indicate that there is no response or response element that is intrinsically affiliative or disaffiliative. The present special issue takes the position that (dis)affiliation in responding actions can be enacted, formulated, and conveyed through a complex interplay of multiple factors such as syntactic formats and prosodic features of the response and their relation to the initiating action, visible conduct of the participants, specific sequential positions of the response, etc., and examines the distinct relevancies and resources for (dis)affiliation in responding actions in different languages.

\section{Alignment in responding actions}

To recapitulate, in Stivers' seminal attempt to explicitly distinguish the two concepts of affiliation and alignment in midtelling sequential environments during storytelling, alignment is conceptualized in terms of the activity in progress, and used to indicate the recipient's support of the "structural asymmetry of the storytelling activity" (Stivers, 2008: 34). Recipients can produce vocal continuers such as $\mathrm{mm} \mathrm{hm}$ and pass up the opportunity to take a full turn in mid-telling environments, supporting the structural asymmetry of the storytelling activity in which the teller retains the floor until story completion.

As with the allied concept of affiliation, Stivers et al. (2011) takes the concept of alignment beyond the context of storytelling, extending the term more generally to cooperation at the structural level. Aligning responses "cooperate by facilitating the proposed activity or sequence, accepting the presuppositions and terms of the proposed action or activity, and matching the formal design preference of the turn" (Stivers et al., 2011: 21). Thus, aligning responses can be constructed by reference to the particular format of the initiating action, as well as by reference to the structure of the sequence and the activity in progress.

A systematic investigation of this structural, formal level of cooperation in responding actions can be found in the growing literature on resistant responses to questioning. A number of conversation-analytic studies focused on the constraining nature of questions and the varying formats and character of responses that resist, and depart from, the terms and constraints of questions - namely, of disaligning responses - although such resistant responses have not always been couched under the rubric of (dis)alignment (see Heritage, 2010; Steensig, 2013).

In particular, polar questions exert multiple constraints on the form of response, and various designs of responses can conform to or resist the constraints, that is, align or disalign with the question, regardless of whether they affiliate or not with the question in terms of action preference (Boyd and Heritage, 2006; Heritage and Raymond, 2012; Raymond, 2003; Sacks, 1987; Stivers and Hayashi, 2010). Type-conforming responses, for instance, are constructed with a lexical item projected by the question, such as yes or no in English, which agrees or disagrees with the proposition at hand within the terms set by the question (Raymond, 2003). These type-conforming responses are aligning responses, acquiescing to and accepting the terms and presuppositions of the question, independently of whether or not they agree and affiliate with expectations embodied in the question. Other forms of confirmations that depart from this type-conformity are disaligning responses, resisting the terms and/or presuppositions of the question in various ways. For instance, repetitional responses in English claim more epistemic rights than the question indexes (Heritage and Raymond, 2012). Of course in English challenges the question's presupposition that both confirmation and disconfirmation are viable answers (Stivers, 2011). Transformative responses in English, Japanese, and Korean resist, and seek to alter, the terms and agenda of the question (Hayashi and Kushida, 2013; Lee, 2011; Stivers and Hayashi, 2010). Also of relevance is research on turn-initial prefacing in English, Japanese, and Russian (Bolden, 2009; Hayashi, 2009; Heritage, 1998). The cumulative body of research on resistant responses to questions shows specific ways in which responding actions can disalign with, and reject, the terms and presuppositions of the initiating action, quite apart from whether they affiliate with the question.

Indeed, such resistant, disaligning responses can be used to achieve cooperation at the level of affective or evaluative stance, that is, affiliation, even when they may be uncooperative on the structural level. For instance, while repetitional 
responses that claim more epistemic rights than the question are disaligning, they can be used as a resource for augmenting affiliation by asserting more agency or knowledge over the response (Heritage and Raymond, 2012; see also Hayano, 2011; Heritage, 2002; Steensig, 2013). Respondents can thus prioritize social affiliation at the cost of alignment (or vice versa), when the two 'conflict' with one another. Note that the prioritizing of affiliation by respondents may not be relevant in some types of activities and contexts, for instance in troubles-telling sequences in service encounters (Jefferson and Lee, 1981) and healthcare consultations (Ruusuvuori, 2005). Affiliative responses to troubles-talk may not be treated as relevant in these institutional contexts.

The construction and understanding of responses along the dimension of alignment may require a complex consideration of the type of initiating actions and activities, contexts in which the sequence occurs, and affiliation, along with various resources available for displaying (dis)alignment and (dis)affiliation across languages. While the concepts of affiliation and alignment are distinct from one another, the design and conduct of responding actions may involve a close interplay (and selection) between the two (see Bolden, this issue).

\section{Contributions to this special issue}

The contributions to this special issue investigate linguistic and interactional resources for constructing (dis)affiliative and (dis)aligning responding actions in different languages. While the methodology used is conversation analysis, the articles are also variously informed by interactional linguistics, which bears upon the relationship between the communicative resources of a language and their deployment for interactional ends (see for instance, Ochs et al., 1996; Selting and Couper-Kuhlen, 2001; Barth-Weingarten et al., 2010).

The first two papers (Tanaka; Luke and Tanaka) explore lexico-syntactic resources deployed to construct affiliative responses to impersonal assessments in English and Cantonese, respectively. As discussed in the sections above, while (dis)affiliative responses for a wide range of initiating actions often share many design features, more recent research indicates that a monolithic treatment of (dis)affiliative responses glosses over distinctive relevancies triggered by particular types of initiating actions (see especially Thompson et al., 2015; also Couper-Kuhlen, 2012; Heritage, 2011; Lindström and Sorjonen, 2013; Selting, 2010). Furthermore, relatively little attention has been given to the syntactic forms of (dis)affiliative responses, and in particular, how the affordances of a language - such as word order and capacity for 'ellipsis' - may contribute toward shaping the responses (but see Hakulinen and Sorjonen, 2009; Steensig and Asmuß, 2005; Tanaka, 2005, 2008).

Against this backdrop, the paper by Tanaka poses the question: given the different grammatical resources afforded by English and Japanese, to what extent do the choices implemented by English speakers for the construction of agreements with prior assessments reflect the underlying grammatical constraints in English (namely, relatively fixed word order and restricted capacity for 'ellipsis') in comparison with what is known for Japanese (namely, word order variability and greater freedom to leave arguments unexpressed)? It is shown that, despite the constraints of English grammar, a limited use of word order variability and ellipsis is nevertheless observed even in English, albeit complemented by other resources that do not rely on syntax. Building on this paper, the piece by Luke and Tanaka directs attention to the case of Cantonese, which has selected grammatical features in common with both English and Japanese. Indeed, while Cantonese resembles English in the sense that word order is an important ingredient in turn-construction, Cantonese shares with Japanese the capacity for leaving arguments unexpressed as well as the ubiquitous deployment of final (predicative) particles. The authors show that, partly as a consequence of this constellation of grammatical features, the construction of agreements with prior assessments in Cantonese has more in common with Japanese than English. The two papers suggest that the structures of affiliative responses - whether in English or Cantonese - offer testimony as to how the lexico-syntactic devices in a language may be mobilized in various ways for augmenting cooperation on the level of affect and action, in ways concordant with the underlying syntactic structure of the carrier language.

Two further papers focus on responses to polar (yes/no) questions which seek information or confirmation, with Bolden examining confirming responses in Russian and Lee looking at disconfirming responses and the sequential trajectories they engender in Korean. As detailed in the sections above, aligning responses accept and conform to the terms and constraints of a polar question, whereas disaligning responses resist and depart from them. This is distinctive from whether responses affiliate or not with the question in terms of action preference, for instance whether they agree or not with the question that seeks information or confirmation. The papers by Bolden and Lee suggest that the processes involved in achieving (dis)alignment and (dis)affiliation in (dis)agreeing, (dis)confirming responses can be rather more complex than hitherto thought.

The paper by Bolden proposes that simple confirmations, even in their unmarked form, are not necessarily used to merely affirm the matter enquired about in Russian. Bolden shows that confirming responses may nevertheless contain elements of disaffiliation and disalignment and resist a question by conveying an incongruent evaluative stance, an incongruent epistemic stance, or by disattending its action implications. Turning attention to disconfirming responses, the 
paper by Lee proposes that while disconfirming responses to polar questions are disaffiliative by their very nature, they tend to develop into sequences orienting toward the achievement of alignment and affiliation in Korean. Lee shows that in third position following disconfirming responses, questioners tend to produce a revised question in alignment with the prior response, seeking to establish and to put on record the correct information, or to achieve common ground with respondents.

While the first four papers described above examine lexicalized responses, last but not least, the papers by Clift and Holt shift attention to laughter - which is shown to play a significant role in shaping a response as (dis)affiliative or (dis) aligning. While fully lexicalized responses are more explicit with regard to the action being implemented, it emerges that the consequences of using a less lexicalized object such as laughter may be more ambiguous, complex and vary significantly depending on the precise sequential environment in which it is featured. The papers look at hitherto unexplored aspects of laughter as a response to prior actions and the unfolding sequence more generally. While laughter has often been associated with something humorous, recent research is unearthing its elusive, contradictory uses, such as to display affiliation or disaffiliation depending on where it occurs within the specific interactional environment (Holt, 2013). Both papers specifically examine laughter occurring in response to, or following, ostensibly non-humorous turn(s), but the relationship between a candidate initiating action and responsive laugher is by no means clear-cut or straightforward. To wit, responsive laughter can target a range of different types of prior actions and positions, such as those produced as initiating actions (e.g. requests) or as responses themselves to some initiating action (e.g. second assessments, response to complaint, answer to question, etc.). It may even simultaneously target the just prior turn as well as orienting to the speaker's own turn preceding the prior turn. Interestingly, responsive laughter may not only be produced by the intended recipient of a prior turn, but likewise by a bystander or over-hearer.

For instance, the paper by Clift looks at laughter which responds to a prior turn by marking it as preposterous and problematic. By displaying a negative stance, laughter in this position is produced and recognized as highly disaffiliative from the turn it targets. But if the laugh-producer is a bystander, the laughter, in disaffiliating from the prior turn, paradoxically serves to affiliate with its recipient. Quite a different use of laugher is discussed in Holt's contribution, in which she investigates laugher which occurs in third position following or in overlap with a response (in second position) to the same speaker's first position turn (which is not explicitly framed as non-serious but contains playful elements). As such, the laughter is responsive to the recipient's turn while also targeting the first turn as well as the sequence-so-far. Holt argues that laughter in this context is one device that is used in order to negotiate mutual alignment between speakers as to whether the first position turn should be treated seriously or non-seriously.

In putting together this special issue, we hope to throw further light on the richness and complexity of responding actions in relation to the notions of (dis)affiliation and (dis)alignment. The first four articles begin with specific kinds of initiating action, namely assessments or polar questions, and explore how (dis)affiliation or (dis)alignment may be contextually accomplished within certain types of responding actions by mustering a wide range of resources which are made available within the host language. Conversely, in the two articles on laughter, the points of departure consist of responsive actions which are either wholly occupied with, or includes laughter, and investigate how laughter may be implicated in the display or performance of (dis)affiliation and (dis)alignment with a prior turn or an earlier part of the sequence. While the abstract principles of affiliation and alignment are no doubt integral dimensions universally oriented to in the construction of responsive actions, it should be apparent that their concrete realization is deeply dependent on their local linguistic and interactional environments.

\section{Acknowledgements}

The idea for this special issue emerged from the 2nd International Workshop on Conversation Analysis held in Singapore in February 2014 on the topic of 'responding actions' in conversational interaction across a range of Asian and Indo-European languages. We are indebted to Yonsei University and Nanyang Technological University for sponsoring the workshop. Our gratitude goes to all the reviewers who provided invaluable suggestions and constructive comments on the papers. We thank Louise Cummings and Anne Bezuidenhout, successive Special Issues Editors of the Journal of Pragmatics, for their helpful support throughout our journey as guest-editors of this special issue. We would also like to thank Rebecca Clift for her insightful suggestions on an earlier version of this editorial, though all remaining imperfections are our responsibility.

\section{References}

Angouri, Jo, Locher, Miram A. (Eds.), 2012. Theorising disagreement. J. Pragmat. 44 (12), 1549-1720 (Special Issue).

Atkinson, J. Maxwell, Heritage, John (Eds.), 1984. Structures of Social Action: Studies in Conversation Analysis. Cambridge University Press, Cambridge.

Barth-Weingarten, Dagmar, Reber, Elisabeth, Selting, Margret (Eds.), 2010. Prosody in Interaction. John Benjamins, Amsterdam.

Bolden, Galina, 2009. Implementing incipient actions: the discourse marker 'so' in English conversation. J. Pragmat. 41 (5), $974-998$. 
Boyd, Elizabeth, Heritage, John, 2006. Taking the patient's medical history: questioning during comprehensive history taking. In: Heritage, J., Maynard, D. (Eds.), Communication in Medical Care: Interactions Between Primary Care Physicians and Patients. Cambridge University Press, Cambridge, pp. 151-184.

Clayman, Steven E., 2002. Sequence and solidarity. In: Lawler, E.J., Thye, S.R. (Eds.), Advances in Group Processes: Group Cohesion, Trust, and Solidarity. Elsevier Science, Oxford, pp. 229-253.

Couper-Kuhlen, Elizabeth, 2012. Exploring affiliation in the reception of conversational complaint stories. In: Peräkylä, A., Sorjonen, M.-L. (Eds.), Emotion in Interaction. Oxford University Press, Oxford, pp. 113-146.

Hakulinen, Auli, Sorjonen, Marja-Leena, 2009. Designing utterances for action: verb repeat responses to assessments. In: Haakana, M., Laakso, M., Lindström, J. (Eds.), Talk in Interaction: Comparative Dimensions. Finnish Literature Society (SKS), Helsinki, pp. 124-151.

Hayano, Kaoru, 2011. Giving support to the claim of epistemic primacy: yo-marked assessments in Japanese. In: Stivers, T., Mondada, L., Steensig, J. (Eds.), The Morality of Knowledge in Conversation. Cambridge University Press, Cambridge, pp. 58-81.

Hayashi, Makoto, 2009. Marking a 'noticing of departure' in talk: eh-prefaced turns in Japanese conversation. J. Pragmat. 41, 2100-2129.

Hayashi, Makoto, Kushida, Shuya, 2013. Responding with resistance to wh-questions in Japanese talk-in-interaction. Res. Lang. Soc. Interact. 46 (3), 231-255.

Heritage, John, 1984. Garfinkel and Ethnomethodology. Polity Press, Cambridge.

Heritage, John, 1998. Oh-prefaced responses to inquiry. Lang. Soc. 27, 291-334.

Heritage, John, 2002. Oh-prefaced responses to assessments: a method of modifying agreement/disagreement. In: Ford, C., Fox, B., Thompson, S. (Eds.), The Language of Turn and Sequence. Oxford University Press, Oxford, pp. 196-224.

Heritage, John, 2010. Questioning in medicine. In: Freed, A.F., Ehrlich, S. (Eds.), "Why Do You Ask?": The Function of Questions in Institutional Discourse. Oxford University Press, New York, pp. 42-68.

Heritage, John, 2011. Territories of knowledge, territories of experience: empathic moments in interaction. In: Stivers, T., Mondada, L., Steensig, J. (Eds.), The Morality of Knowledge in Conversation. Cambridge University Press, Cambridge, pp. 159-183.

Heritage, John, Raymond, Geoffrey, 2012. Navigating epistemic landscapes: acquiescence, agency and resistance in responses to polar questions. In: de Ruiter, J.P. (Ed.), Questions: Formal, Functional, and Interactional Perspectives. Cambridge University Press, Cambridge, pp. 179-192.

Holt, Elizabeth, 2013. Conversation analysis and laughter. In: Chapelle, C.A. (Ed.), The Encyclopedia of Applied Linguistics. Blackwell Publishing, OxfordISBN 9781405198431.

Jefferson, Gail, 1988. On the sequential organization of troubles-talk in ordinary conversation. Soc. Probl. 35, 418-441.

Jefferson, Gail, 2002. Is 'no' an acknowledgement token? Comparing American and British uses of (+)/(-) tokens. J. Pragmat. 34, 1345-1383.

Jefferson, Gail, Lee, John R.E., 1981. The rejection of advice: managing the problematic convergence of a 'troubles-telling' and a 'service encounter'. J. Pragmat. 5, 399-422.

Kendrick, Kobin H., Torreira, Francisco, 2015. The timing and construction of preference: a quantitative study. Discourse Process. 52 (4), 255289.

Lee, Seung-Hee, 2011. Responding at higher level: activity progressivity in calls for service. J. Pragmat. 43, 904-917.

Levinson, Stephen C., 1983. Pragmatics. Cambridge University Press, Cambridge.

Lindström, Anna, Sorjonen, Marja-Leena, 2013. Affiliation in conversation. In: Sidnell, J., Stivers, T. (Eds.), The Handbook of Conversation Analysis. Wiley-Blackwell, Boston, pp. 350-369.

Ochs, Elinor, Schegloff, Emanuel A., Thompson, Sandra A. (Eds.), 1996. Interaction and Grammar. Cambridge University Press, Cambridge.

Pomerantz, Anita, 1984. Agreeing and disagreeing with assessments: some features of preferred/dispreferred turn shapes. In: Atkinson, J.M., Heritage, J. (Eds.), Structures of Social Action: Studies in Conversation Analysis. Cambridge University Press, Cambridge, pp. 57-101.

Pomerantz, Anita, Heritage, John, 2013. Preference. In: Sidnell, J., Stivers, T. (Eds.), The Handbook of Conversation Analysis. Wiley-Blackwell, Boston, pp. 210-228.

Raymond, Geoffrey, 2003. Grammar and social organization: yes/no interrogatives and the structure of responding. Am. Sociol. Rev. 68, 939967.

Ruusuvuori, Johanna, 2005. 'Empathy' and 'sympathy' in action: attending to patients' troubles in Finnish homeopathic and general practice consultations. Soc. Psychol. Q. 68, 204-222.

Sacks, Harvey, 1973. The preference for agreement in natural conversation. In: Paper presented at the Linguistic Institute,

Sacks, Harvey, 1987. On the preferences for agreement and contiguity in sequences in conversation. In: Button, G., Lee, J.R.E. (Eds.), Talk and Social Organization. Multilingual Matters, Clevedon, pp. 54-69.

Schegloff, Emanuel A., 2007. Sequence Organization in Interaction: A Primer in Conversation Analysis. Cambridge University Press, Cambridge.

Selting, Margret, 2010. Affectivity in storytelling: an analysis of displays of anger or indignation in complaint stories. Pragmatics 20 (2), $229-277$.

Selting, Margaret, Couper-Kuhlen, Elizabeth (Eds.), 2001. Studies in Interactional Linguistics. John Benjamins, Amsterdam.

Sorjonen, Marja-Leena, 2001. Responding in Conversation: A Study of Response Particles in Finnish. John Benjamins, Amsterdam.

Steensig, Jakob, 2013. Conversation analysis and affiliation and alignment. In: Chapelle, C. (Ed.), The Encyclopedia of Applied Linguistics. WileyBlackwell, Boston, pp. 944-948.

Steensig, Jakob, Asmuß, Birte, 2005. Notes on disaligning 'yes but' initiated utterances in German and Danish conversations: two construction types for dispreferred responses. In: Hakulinen, A., Selting, M. (Eds.), Syntax and Lexis in Conversation: Studies on the Use of Linguistic Resources in Talk-in-interaction. Studies in Discourse and Grammar, vol. 17. John Benjamins, Amsterdam, pp. 349-373.

Stivers, Tanya, 2008. Stance, alignment, and affiliation during storytelling: when nodding is a token of affiliation. Res. Lang. Soc. Interact. 41, 3157.

Stivers, Tanya, 2011. Morality and question design: 'of course' as contesting a presupposition of askability. In: Stivers, T., Mondada, L., Steensig, J. (Eds.), The Morality of Knowledge in Conversation. Cambridge University Press, Cambridge, pp. 82-106.

Stivers, Tanya, Hayashi, Makoto, 2010. Transformative answers: one way to resist a question's constraints. Lang. Soc. 29, 1-25.

Stivers, Tanya, Rossano, Federico, 2010. Mobilizing response. Res. Lang. Soc. Interact. 43, 3-31. 
Stivers, Tanya, Enfield, Nick J., Brown, Penelope, Englert, Christina, Hayashi, Makoto, Heinemann, Trine, Hoymann, Gertie, Rossano, Federico, de Ruiter, Jan Peter, Yoon, Kyung-Eun, Levinson, Stephen C., 2009. Universals and cultural variation in turn-taking in conversation. Proc. Natl. Acad. Sci. 106 (26), 10587-10592.

Stivers, Tanya, Enfield, Nick J., Levinson, Stephen C. (Eds.), 2010. Question-response sequences in conversation across ten languages. J. Pragmat. 42 (8), 2615-1798 (Special Issue).

Stivers, Tanya, Mondada, Lorenza, Steensig, Jakob, 2011. Knowledge, morality, and affiliation in social interaction. In: Stivers, T., Mondada, L., Steensig, J. (Eds.), The Morality of Knowledge in Conversation. Cambridge University Press, Cambridge, pp. 3-24.

Tanaka, Hiroko, 2005. Grammar and the "timing" of social action: word order and preference organization in Japanese. Lang. Soc. 34, 389-430.

Tanaka, Hiroko, 2008. Delaying dispreferred responses in English: from a Japanese perspective. Lang. Soc. 37 (4), $487-513$.

Thompson, Sandra A., Fox, Barbara A., Couper-Kuhlen, Elizabeth, 2015. Grammar in Everyday Talk: Building Responsive Actions. Cambridge University Press, Cambridge.

Seung-Hee Lee

Department of English Language and Literature, Yonsei University, 50 Yonsei-ro, Seodaemun-gu, Seoul 03722, South Korea

Hiroko Tanaka*
Department of Sociology, University of Essex, Wivenhoe Park, Colchester, Essex CO4 3SQ,

United Kingdom

${ }^{*}$ Corresponding author

E-mail addresses: htanaka@essex.ac.uk (H. Tanaka) seunglee@yonsei.ac.kr (S.-H. Lee). 